\title{
Comparison of high flow nasal oxygen and conventional nasal cannula during gastrointestinal endoscopic sedation in the prone position: a randomized trial
}

\section{Comparaison de l'oxygénothérapie nasale à haut débit versus une lunette nasale conventionnelle pendant une sédation pour endoscopie gastro-intestinale en position ventrale : une étude randomisée}

\author{
Seung Hyun Kim, MD, PhD $\cdot$ Seungmin Bang, MD, PhD $\cdot$ Ki-Young Lee, MD, PhD • \\ Seung Woo Park, MD, PhD · Jeong Youp Park, MD, PhD · Hee Seung Lee, MD, PhD • \\ Hanseul Oh, MD $\cdot$ Young Jun Oh, MD, PhD
}

Received: 1 April 2020/Revised: 3 June 2020/ Accepted: 28 June 2020/Published online: 6 January 2021

(C) Canadian Anesthesiologists' Society 2021

\begin{abstract}
Purpose Deep sedation for endoscopic retrograde cholangiopancreatography (ERCP) can be challenging in elderly patients in the prone position. This study investigated the effect of a high flow nasal oxygen (HFNO) delivery system on oxygenation in this procedure compared with that of conventional nasal cannula oxygen administration.

Methods A prospective randomized trial was conducted using HFNO and conventional nasal cannula in patients undergoing ERCP in the prone position. For each patient, the lowest oxygen saturation $\left(\mathrm{SpO}_{2}\right)$, the incidence of hypoxemia defined as an $\mathrm{SpO}_{2}$ below 90\%, and
\end{abstract}

This manuscript is accompanied by an editorial. Please see Can J Anesth 2020; this issue.

S. H. Kim, MD, PhD - K.-Y. Lee, MD, PhD

Y. J. Oh, MD, PhD ( $\square)$

Department of Anesthesiology and Pain Medicine, Anesthesia and Pain Research Institute, Severance Hospital, Yonsei

University College of Medicine, Seoul, Korea

e-mail: YJOH@yuhs.ac

S. Bang, MD, PhD $\cdot$ S. W. Park, MD, PhD

J. Y. Park, MD, PhD - H. S. Lee, MD, PhD

Division of Gastroenterology, Department of Internal Medicine,

Yonsei University College of Medicine, Seoul, Korea

H. Oh, MD

Department of Anesthesiology and Pain Medicine, Severance

Hospital, Yonsei University College of Medicine, Seoul, Korea interruptions due to airway interventions were recorded during the procedure.

Results The lowest mean (standard deviation) $\mathrm{SpO}_{2}$ recorded during the procedure was higher in the HFNO group than in the conventional control group [99.8 (0.6)\% vs 95.1 (7.3)\%; mean difference, 4.7\%; 95\% confidence interval, $2.3 \%$ to $7.1 \% ; P$ Group $x$ Time $<0.001]$. While the lowest $\mathrm{SpO}_{2}$ during the procedure was lower than the baseline $\mathrm{SpO}_{2}$ in the control group, the lowest $\mathrm{SpO}_{2}$ during the procedure was higher than the baseline $\mathrm{SpO}_{2}$ in the HFNO group. Hypoxemia occurred only in the control group $(n=7 ; 19 \% ; P=0.01)$. Procedural interruptions, including discontinuation of sedation, patient stimulation, and jaw thrusting, occurred only in the control group $(n=$ 9 [25\%], $n=10$ [28\%], and $n=10$ [28\%] cases, respectively; $P=0.001$ for each).

Conclusion In contrast to conventional nasal cannula, high flow nasal oxygen provided adequate oxygenation without causing procedural interruptions during ERCP, suggesting that HFNO may be used as a standard oxygen delivery method during these procedures.

Trial registration $w w w$.ClinicalTrials.gov (NCT03872674); registered 11 March 2019.

Résumé

Objectif $L a$ sédation profonde pour cholangiopancréatographie rétrograde endoscopique (CPRE) peut être difficile à réaliser chez des patients âgés en position ventrale. Cette étude a explorél'effet d'un 
système d'oxygénothérapie nasale à haut débit (ONHD) sur l'oxygénation pendant cette intervention par rapport à l'administration conventionnelle d'oxygène via une lunette nasale.

Méthode Une étude randomisée prospective a été réalisée en utilisant une ONHD ou une lunette nasale conventionnelle chez des patients subissant une CPRE en position ventrale. Pour chaque patient, la saturation en oxygène $\left(\mathrm{SpO}_{2}\right)$ la plus basse, l'incidence d'hypoxémie définie en tant qu'une $\mathrm{SpO}_{2}$ inférieure à $90 \%$, et les interruptions provoquées par des interventions au niveau des voies aériennes ont été enregistrées au cours de l'intervention.

Résultats $\mathrm{La} \mathrm{SpO}_{2}$ moyenne (écart type) la plus basse enregistrée pendant l'intervention était plus élevée dans le groupe ONHD que dans le groupe témoin conventionnel [99,8 (0,6) \% vs 95,1 (7,3) \%; différence moyenne, 4,7\%; intervalle de confiance $95 \%$, 2,3 \% à 7,1 \%; $P$ Groupe $x$ Temps $<0,001]$. Alors que la $\mathrm{SpO}_{2}$ la plus basse pendant l'intervention était plus basse que la $\mathrm{SpO}_{2}$ de base dans le groupe témoin, la $\mathrm{SpO}_{2}$ la plus basse pendant l'intervention était plus élevée que la $\mathrm{SpO}_{2}$ de base dans le groupe ONHD. L'hypoxémie n'est survenue que dans le groupe témoin ( $n=7 ; 19 \% ; P=0,01)$. Il n'y a eu d'interruptions de l'intervention, y compris la cessation de la sédation, la stimulation du patient et le déplacement de la mâchoire inférieure vers l'avant, que dans le groupe témoin ( $n=9$ [25\%], $n=10$ [28\%], et $n=10$ [28\%] cas, respectivement; $P=0,001$ pour chaque intervention).

Conclusion Comparativement à une lunette nasale conventionnelle, l'oxygénothérapie nasale à haut débit a procuré une oxygénation adéquate sans provoquer d'interruptions de l'intervention pendant une CPRE, suggérant que cette modalité pourrait être utilisée comme méthode standard d'oxygénothérapie pendant de telles interventions.

Enregistrement de l'étude $w w w$.ClinicalTrials.gov (NCT03872674); enregistrée le 11 mars 2019.

Keywords endoscopy · high flow nasal oxygen · sedation

A positive relationship between conscious sedation during gastrointestinal endoscopy and procedure success and patient satisfaction has been established. ${ }^{1-3}$ Nevertheless, sedation can cause complications, such as respiratory depression and hypoxemia, requiring careful monitoring and adequate airway intervention.

Patients undergoing endoscopic retrograde cholangiopancreatography (ERCP) are often older than those who undergo other endoscopic procedures. ${ }^{4}$
Furthermore, ERCP is often a more invasive procedure, requiring deeper sedation than other procedures such as routine upper endoscopies or colonoscopies. ${ }^{5-7}$ Most ERCP procedures are performed with the patient in the prone position for procedural ease, leading to an increased risk of hypoxemia and hypoventilation due to upper airway obstruction. ${ }^{8}$ In addition, given that endoscopic devices reach the lesion through the oral cavity, it is often difficult for anesthesiologists to access patients' airways, thus limiting ventilation assistance procedures during gastrointestinal endoscopy. If hypoxemia does not improve after discontinuing sedation, patient stimulation, jaw thrust, or the insertion of a nasopharyngeal airway device, procedures may be interrupted or even terminated prematurely. ${ }^{9,10}$ Therefore, maintaining airway stability during sedation is important for patient safety and procedural success.

OptiFlow THRIVE (Fisher and Paykel Healthcare, Panmure, Auckland, New Zealand) is a high flow nasal oxygen (HFNO) delivery system. Unlike conventional high flow systems, such as the Venturi mask, OptiFlow THRIVE supplies humidified and heated air to improve patient comfort. OptiFlow THRIVE has further been reported to improve oxygenation in patients with acute respiratory failure in the intensive care unit and emergency room. ${ }^{11,12}$ Accordingly, it may replace conventional oxygen therapy in intensive care units and have applications in other domains, including the operating room and bronchoscopy units. ${ }^{13,14}$

Sedation for ERCP is particularly challenging as deep sedation is required in elderly patients who must maintain a prone position. We hypothesized that a HFNO system would maintain oxygenation in patients undergoing ERCP in the prone position more effectively than conventional nasal cannula oxygen administration.

\section{Methods}

The present study's protocol was approved by the Institutional Review Board of the Yonsei University Health System, Seoul, South Korea (\#1-2018-0082, Chairperson Prof M. Kim) on 11 February 2019, and was registered at ClinicalTrials.gov (NCT03872674). All authors had access to the study data. Written informed consent was obtained from all patients enrolled in the study, which was conducted in April 2019. The study population consisted of 72 patients aged $20 \mathrm{yr}$ and older with American Society of Anesthesiologists physical status class I-IV, and who underwent ERCP in the prone position. Patients with altered mental status, dementia, cognitive disorders, intubation, tracheostomies, need for oxygen therapy due to pre-existing disease, pregnancy, recent 
history of nasal bleeding, or allergy to propofol were excluded. All patients were randomly allocated to either the control group (undergoing conventional nasal cannula oxygen administration) or the HFNO group in a 1:1 ratio using a computer-generated random code generator. Because the oxygen delivery devices did not look the same, endoscopists, anesthesiologists, and patients were not blinded to the results of randomization. ERCP procedures were completed by one of four expert endoscopists and sedation was delivered by anesthesiologists trained in endoscopic sedation.

\section{Sedation procedure}

Upon their arrival in the endoscopy room, patients were turned to the prone position and standard monitoring, including pulse oximetry, non-invasive blood pressure monitoring, and electrocardiography were performed in all cases. As a capnography sensor could not be connected to the HFNO system, capnography monitoring was performed only in the control group. After establishing standard monitoring, preoxygenation was performed for 1 minute. Then, in the control group, $100 \%$ oxygen was administered at $5 \mathrm{~L} \cdot \mathrm{min}^{-1}$ via a nasal cannula throughout the procedure. In the HFNO group, $100 \%$ oxygen was administered at 50 $\mathrm{L} \cdot \mathrm{min}^{-1}$ via an HFNO system (OptiFlow THRIVE, Fisher and Paykel Healthcare, Panmure, Auckland, New Zealand) throughout the procedure. A bolus of $0.5 \mathrm{mg} . \mathrm{kg}^{-1}$ propofol and $1.0 \mu \mathrm{g}$ fentanyl IV was delivered followed by continuous infusion of propofol $\left(30 \mu \mathrm{g} \cdot \mathrm{min}^{-1} \mathrm{~kg}^{-1}\right)$. The targeted level of sedation was equivalent to an Observer Assessment of Awareness and Sedation Scale (MOAA/S) score of less than 3 in all patients. Ten milligrams of propofol or $0.5 \mu \mathrm{g} \cdot \mathrm{kg}^{-1}$ of fentanyl were administered when sedation or analgesia was insufficient, respectively. The need for sedatives or analgesics was determined by the attending anesthesiologist after a visual assessment of the patient's irritability. Any interventions including discontinuation of propofol, patient stimulation, jaw thrust, nasal airway insertion, or conversion to HFNO were performed at the anesthesiologist's discretion based on the presence of desaturation or apnea. At the end of the procedure, the HFNO system was replaced with a nasal cannula and end-tidal carbon dioxide $\left(\mathrm{CO}_{2}\right)$ was recorded using capnography.

\section{Outcome measures}

The primary outcome in the present study was the lowest oxygen saturation measured via pulse oximetry during the procedure. Secondary outcomes included the incidence of hypoxemia (defined as oxygen saturation $<90 \%$ ), duration of hypoxemia, procedure interruptions due to airway interventions during the procedure (e.g., discontinuing sedation, patient stimulation, jaw thrust, nasal airway insertion), end-tidal $\mathrm{CO}_{2}$ at the end of the procedure, and early procedure termination related to sedation.

\section{Statistical analyses}

Previously, the mean (standard deviation [SD]) of the lowest $\mathrm{SpO}_{2}$ in patients during sedation in control and HFNO patients were reported to be 91.0 (5.1)\% and 95.4 (5.9)\%, respectively. ${ }^{14}$ Given a $10 \%$ dropout rate, 74 patients were calculated to provide $90 \%$ power at a significance level of 0.05 .

Descriptive data were presented as mean (SD) for continuous variables, and as numbers (percentage) for categorical variables. For between-group comparisons, Fisher's exact tests were used for categorical variables (e.g., incidence of hypoxemia, procedure interruptions) and independent $t$-tests were used for continuous variables (e.g., end-tidal $\mathrm{CO}_{2}$ at procedure culmination). The repeated variable (oxygen saturation) was analyzed using a linear mixed model with random intercepts, whereby group, time, and their interaction (i.e., group $\times$ time) were modelled as the fixed effects. Post hoc analysis with Bonferroni correction for within-group comparison and between-group comparison was performed for multiple comparisons. All statistical analyses were performed using SPSS Statistics for Windows (version 25; IBM Corp., Armonk, NY, USA) or SAS (version 9.4, SAS Inc., Cary, NC, USA).

\section{Results}

Two of the 74 patients deemed eligible for this study were excluded because of procedure plan changes involving patient position. Consequently, 72 patients were enrolled: 36 in the control group and 36 in the HFNO system group (Figure). Baseline patient demographics including age, sex, body mass index, American Society of Anesthesiologists physical status, history of pulmonary comorbidities, and smoking status were comparable between the two groups (Table 1). One patient in each group had a history of sleep apnea.

As shown in Table 2, there was no difference in the baseline $\mathrm{SpO}_{2}$ before preoxygenation between the two groups. Nevertheless, the lowest mean (SD) $\mathrm{SpO}_{2}$ during the procedure was different between the HFNO group and the control group [99.8 (0.6)\% vs 95.1 (7.3)\%; mean 
Table 1 Baseline patient characteristics

\begin{tabular}{|c|c|c|}
\hline & $\begin{array}{l}\text { Control group } \\
n=36\end{array}$ & $\begin{array}{l}\text { HFNO group } \\
n=36\end{array}$ \\
\hline Age (yr) & $67.3(14.4)$ & $65.3(13.4)$ \\
\hline Sex (male/female) & $\begin{array}{l}25 / 11(69.4 \% / \\
30.6 \%)\end{array}$ & $\begin{array}{l}22 / 14(61.1 \% / \\
38.9 \%)\end{array}$ \\
\hline BMI $\left(\mathrm{kg} \cdot \mathrm{m}^{-2}\right)$ & $22.1(3.5)$ & $23.1(4.1)$ \\
\hline ASA (I-II/III-IV) & $\begin{array}{l}21 / 15(58.3 \% / \\
41.7 \%)\end{array}$ & $\begin{array}{c}19 / 17(52.8 \% / \\
47.2 \%)\end{array}$ \\
\hline $\begin{array}{l}\text { Pulmonary comorbidities ( } n \text {, } \\
\% \text { ) }\end{array}$ & $2(5.6)$ & $3(8.3)$ \\
\hline History of smoking $(n, \%)$ & $8(22.2)$ & $7(19.4)$ \\
\hline $\begin{array}{l}\text { Obstructive sleep apnea ( } n \text {, } \\
\%)\end{array}$ & $1(2.8)$ & $1(2.8)$ \\
\hline \multicolumn{3}{|l|}{ Preoperative lab } \\
\hline $\begin{array}{l}\text { Aspartate aminotransferase } \\
\left(\mathrm{AST}, \mathrm{IU} \cdot \mathrm{L}^{-1}\right)\end{array}$ & $72.3(77.8)$ & $93.9(132.6)$ \\
\hline $\begin{array}{l}\text { Alanine aminotransferase } \\
\left(\mathrm{ALT}, \mathrm{IU} \cdot \mathrm{L}^{-1}\right)\end{array}$ & $74.1(98.4)$ & $86.9(107.3)$ \\
\hline Total bilirubin $\left(\mathrm{mg} \cdot \mathrm{dL}^{-1}\right)$ & $2.5(3.0)$ & $3.8(5.4)$ \\
\hline $\begin{array}{l}\text { Blood urea nitrogen } \\
\left(\mathrm{mg} \cdot \mathrm{dL}^{-1}\right)\end{array}$ & $16.6(10.1)$ & $15.4(8.3)$ \\
\hline Creatinine $\left(\mathrm{mg} \cdot \mathrm{dL}^{-1}\right)$ & $1.0(0.9)$ & $0.8(0.3)$ \\
\hline \multicolumn{3}{|l|}{ Data on the ERCP procedure } \\
\hline $\begin{array}{l}\text { Total procedure time } \\
\text { (minutes) }\end{array}$ & $15.3(7.3)$ & $17.5(8.2)$ \\
\hline Total propofol dose (mg) & $90.6(38.2)$ & $110.3(54.0)$ \\
\hline Total fentanyl dose $(\mu \mathrm{g})$ & $99.2(37.1)$ & $107.2(34.8)$ \\
\hline
\end{tabular}

Data are presented as mean (standard deviation) for continuous variables and count (percentage) for categorical variables. ASA = American Society of Anesthesiologists; BMI = body mass index; $\mathrm{ERCP}=$ endoscopic retrograde cholangiopancreatography; $\mathrm{HFNO}=$ high flow nasal oxygen.

difference, $4.7 \%$; $95 \%$ confidence interval, $2.3 \%$ to $7.1 \%$; $\left.P_{\text {Group } x \text { Time }}<0.0001\right]$. While the lowest $\mathrm{SpO}_{2}$ during the procedure was lower than the baseline $\mathrm{SpO}_{2}$ in the control group, the lowest $\mathrm{SpO}_{2}$ during the procedure was higher than the baseline $\mathrm{SpO}_{2}$ in the HFNO group.

Hypoxemia occurred only in the control group (Table 2). Interventions for hypoxemia or apnea including discontinuing sedation, patient stimulation, and jaw thrust were also performed only in the control group. A nasal airway was inserted during the procedure in only one case in the control group. End-tidal $\mathrm{CO}_{2}$ values were available for 68 patients. In the remaining four patients, we were unable to detect end-tidal $\mathrm{CO}_{2}$ values because of shallow breathing. End-tidal $\mathrm{CO}_{2}$ was lower in the HFNO group than in the control group. There were no procedure interruptions due to sedation in the present study.

The procedure time, defined as the span of time from scope insertion to withdrawal, was comparable between the two groups. The propofol and fentanyl doses used during the procedure were also comparable between the two groups. All patients in the present study were transferred to general wards in the endoscopy recovery room with no sedation-related complications.

\section{Discussion}

The present study revealed that HFNO use could improve oxygenation during ERCP in the prone position compared with conventional management using a nasal cannula. In addition, no episodes of hypoxemia or hypercapnia occurred with HFNO use. This was the first randomizedcontrolled trial to evaluate the safety of the HFNO oxygen supply system in an endoscopic procedure and substantiated the future application of this technique to standard management in these procedures.

The lowest $\mathrm{SpO}_{2}$ detected in the HFNO group was $98 \%$. As a result, anesthesiologists did not perform any airway interventions during the procedure. This result was consistent with previous studies on dental procedures and awake fibreoptic intubation, which have reported sedation without hypoxemia or airway interventions. ${ }^{13,15}$ High flow rates provided by this system could have exceed the patient's peak inspiratory flow, reducing oxygen dilution with ambient air. High flow nasal oxygen offers a number of additional benefits. While a high fraction of inspired oxygen $\left(\mathrm{F}_{\mathrm{I}} \mathrm{O}_{2}\right)$ is maintained with a high flow rate, warm and humidified air minimizes dryness in the upper airway, reducing patient discomfort and the risk of nasal bleeding. Previous studies have reported improvements in arterial oxygenation in patients with acute hypoxemic respiratory failure, post-extubation respiratory failure, and acute cardiogenic pulmonary edema in intensive care units. ${ }^{16-19}$ In contrast, conventional nasal cannulas can provide a low flow of oxygen (up to approximately $6 \mathrm{~L} \cdot \mathrm{min}^{-1}$ ), far less than a normal individual's inspiratory flow rate (approximately $15 \mathrm{~L} \cdot \mathrm{min}^{-1}$ ). Even though $100 \%$ oxygen was delivered via a nasal cannula, since it was diluted with ambient air, $\mathrm{FiO}_{2}$ delivered via conventional methods was less than 0.4, while $\mathrm{F}_{1} \mathrm{O}_{2}$ delivered with ERCP may have been even lower because of mouth opening.

Furthermore, in the present study, hypercapnia, as measured via capnography at the end of the procedure in the high flow oxygen group, did not occur. This suggests 
Table 2 Comparison of outcomes between the HFNO and control groups during ERCP

\begin{tabular}{|c|c|c|c|}
\hline & $\begin{array}{l}\text { Control group } \\
n=36\end{array}$ & $\begin{array}{l}\text { HFNO group } \\
n=36\end{array}$ & $P$ value \\
\hline $\mathrm{SpO}_{2}(\%)$ & & & 0.0001 \\
\hline Baseline $\mathrm{SpO}_{2}(\%)$ & $98.2(1.6)$ & $97.5(1.7)$ & \\
\hline Lowest $\mathrm{SpO}_{2}(\%)$ during procedure & $95.1(7.3)^{*}$ & $99.8(0.6)^{* \dagger}$ & \\
\hline \multicolumn{4}{|l|}{ Hypoxemia } \\
\hline Incidence, $n(\%)$ & 7 (19) & $0(0)$ & 0.011 \\
\hline Duration (sec) & $17.4(11.2)$ & $0.0(0.0)$ & $\ldots$ \\
\hline Procedural interruption, $n(\%)$ & $10(28)$ & $0(0)$ & 0.001 \\
\hline Discontinued sedation & $9(25)$ & $0(0)$ & 0.002 \\
\hline Patient stimulation & $10(28)$ & $0(0)$ & 0.001 \\
\hline Jaw thrusting & $10(28)$ & $0(0)$ & 0.001 \\
\hline Nasal airway insertion & $1(3)$ & $0(0)$ & $>0.999$ \\
\hline $\mathrm{EtCO}_{2}$ at end of procedure $(\mathrm{mmHg})$ & $33.9(7.4)$ & $30.4(6.6)$ & 0.045 \\
\hline
\end{tabular}

Data are presented as mean (standard deviation) for continuous variables and count (percentage) for categorical variables.

$* P<0.05$ compared with the baseline. $\dagger P<0.05$ compared with the control group.

$\mathrm{ERCP}=$ endoscopic retrograde cholangiopancreatography; $\mathrm{EtCO}_{2}=$ end-tidal carbon dioxide $; \mathrm{HFNO}=$ high flow nasal oxygen; $\mathrm{SpO} \mathrm{O}_{2}=$ oxygen saturation.

that this system may have prevented desaturation due to shunting or ventilation perfusion mismatch as well as hypoventilation. A high flow can flush pharyngeal dead space, minimizing $\mathrm{CO}_{2}$ reinhalation and possibly improving hypoventilation. ${ }^{20}$ Adequate oxygenation and $\mathrm{CO}_{2}$ washout have been reported in previous studies of pharyngeal and laryngeal surgery with apneic oxygenation using a high flow oxygen system and muscle relaxant. ${ }^{20-22}$ Nevertheless, sedation should still be carefully monitored, even when the HFNO system is used, especially among patients with severe pulmonary comorbidities. A previous study reported that hypoxemia occurred in patients with pulmonary comorbidities during bronchoscopy while receiving HFNO ${ }^{14}$ In contrast, the present study included only three patients (8\%) with pulmonary comorbidities in the HFNO group, and this may account for the lack of any sedation-related procedure terminations.

The present study has some limitations. First, the oxygen supply systems (the conventional vs HFNO devices) did not look the same so endoscopists, anesthesiologists, and patients were not blinded to group allocation. Second, we did not perform arterial blood gas analysis or use other markers for ventilation, such as minute ventilation. We recorded only end-tidal $\mathrm{CO}_{2}$ levels via nasal cannula capnography. Given this, our assessment of $\mathrm{CO}_{2}$ retention may have been affected by confounding factors such as the patient's effort to breathe. Third, we excluded all patients with a history of respiratory diseases requiring oxygen therapy. Further studies including high- risk elderly patients are thus needed to elucidate the effects of the HFNO delivery system on complications such as sedation-related early termination of procedures.

Conventional oxygen supply via a nasal cannula is insufficient for deep sedation during ERCP cases because it only delivers at a $\mathrm{F}_{1} \mathrm{O}_{2}$ less than 0.4 . In contrast, the Venturi mask, a conventional high flow oxygen system, can deliver oxygen with a $\mathrm{F}_{1} \mathrm{O}_{2}$ of up to 0.6 and flow rate of $30-50$ $\mathrm{L} \cdot \mathrm{min}^{-1}$. Nevertheless, this device often causes some patient discomfort and nasal inflammation or bleeding. Furthermore, it is impossible to use such conventional masks for ERCP procedures utilizing an oral endoscopic approach. Moreover, endoscopic masks, which are specially designed for administering oxygen during endoscopic procedures, are inconvenient to use and can interfere with the procedure, especially when a patient is in the prone position. High flow nasal oxygen systems circumvent these limitations by providing $100 \%$ oxygen with a humidifier and heating system, thus improving oxygenation and patient discomfort. Patient safety also benefits from HFNO systems as procedural success is improved and endoscopists are free to focus on the procedure in a more stable oxygen delivery environment.

In conclusion, the results of the present study showed that, compared with the conventional nasal cannula, the HFNO system provides adequate oxygenation without procedure interruption in patients undergoing ERCP in the prone position. Given this, we suggest that this system be used as a standard oxygen delivery method in ERCP. 


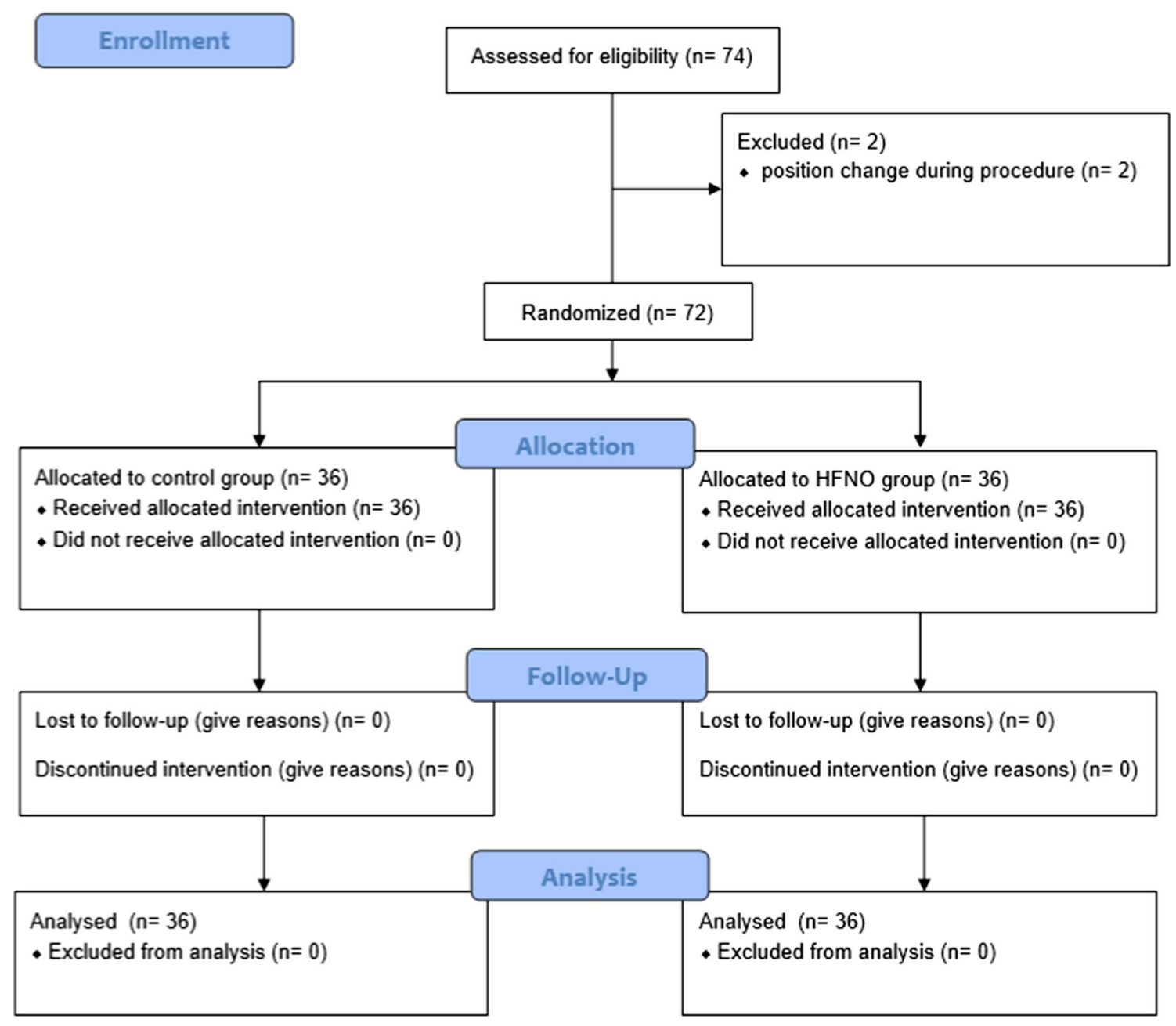

Figure Study flow diagram. HFNO = high flow nasal oxygen.

Author contributions Seung Hyun Kim, Ki-Young Lee, and Young Jun Oh contributed to study concept and design; acquisition, analysis, and interpretation of data; and drafting and critical revision of the manuscript. Seungmin Bang, Seung Woo Park, Jeong Youp Park, Hee Seung Lee, and Hanseul Oh contributed to acquisition, analysis, and interpretation of data, and critical revision of the manuscript.

Disclosures None.

Funding statement None.

Editorial responsibility This submission was handled by Dr. Philip M. Jones, Associate Editor, Canadian Journal of Anesthesia.

\section{References}

1. McQuaid KR, Laine L. A systematic review and meta-analysis of randomized, controlled trials of moderate sedation for routine endoscopic procedures. Gastrointest Endosc 2008; 67: 910-23.
2. Standards of Practice Committee, Lichtenstein DR, Jagannath S, Baron TH, et al. Sedation and anesthesia in GI endoscopy. Gastrointest Endosc 2008; 68: 205-16.

3. Waring JP, Baron TH, Hirota WK, et al. Guidelines for conscious sedation and monitoring during gastrointestinal endoscopy. Gastrointest Endosc 2003; 58: 317-22.

4. Rigg JD, Watt TC, Tweedle DE, Martin DF. Oxygen saturation during endoscopic retrograde cholangiopancreatography: a comparison of two protocols of oxygen administration. Gut 1994; 35: 408-11.

5. Riphaus A, Stergiou N, Wehrmann T. Sedation with propofol for routine ERCP in high-risk octogenarians: a randomized, controlled study. Am J Gastroenterol 2005; 100: 1957-63.

6. Patel S, Vargo JJ, Khandwala F, et al. Deep sedation occurs frequently during elective endoscopy with meperidine and midazolam. Am J Gastroenterol 2005; 100: 2689-95.

7. Chainaki IG, Manolaraki MM, Paspatis GA. Deep sedation for endoscopic retrograde cholangiopacreatography. World J Gastrointest Endosc 2011; 3: 34-9.

8. Ferreira LE, Baron TH. Comparison of safety and efficacy of ERCP performed with the patient in supine and prone positions. Gastrointest Endosc 2008; 67: 1037-43.

9. Yang JF, Farooq P, Zwilling K, Patel D, Siddiqui AA. Efficacy and safety of propofol-mediated sedation for outpatient 
endoscopic retrograde cholangiopancreatography (ERCP). Dig Dis Sci 2016; 61: 1686-91.

10. Pieri $M$, Landoni $G$, Cabrini $L$. Noninvasive ventilation during endoscopic procedures: rationale, clinical use, and devices. J Cardiothorac Vasc Anesth 2018; 32: 928-34.

11. Lenglet H, Sztrymf B, Leroy C, Brun P, Dreyfuss D, Ricard JD. Humidified high flow nasal oxygen during respiratory failure in the emergency department: feasibility and efficacy. Respir Care 2012; 57: 1873-8.

12. Roca O, Riera J, Torres F, Masclans JR. High-flow oxygen therapy in acute respiratory failure. Respir Care 2010; 55: 408-13.

13. Badiger $S$, John M, Fearnley RA, Ahmad I. Optimizing oxygenation and intubation conditions during awake fibre-optic intubation using a high-flow nasal oxygen-delivery system. Br J Anaesth 2015; 115: 629-32.

14. Douglas N, Ng I, Nazeem F, et al. A randomised controlled trial comparing high-flow nasal oxygen with standard management for conscious sedation during bronchoscopy. Anaesthesia 2018; 73: 169-76.

15. Sago T, Harano N, Chogyoji Y, Nunomaki M, Shiiba S, Watanabe $S$. A nasal high-flow system prevents hypoxia in dental patients under intravenous sedation. J Oral Maxillofac Surg 2015; 73 : 1058-64.

16. Lee JH, Rehder KJ, Williford L, Cheifetz IM, Turner DA. Use of high flow nasal cannula in critically ill infants, children, and adults: a critical review of the literature. Intensive Care Med 2013; 39: 247-57.
17. Papazian L, Corley A, Hess D, et al. Use of high-flow nasal cannula oxygenation in ICU adults: a narrative review. Intensive Care Med 2016; 42: 1336-49.

18. Sztrymf B, Messika J, Bertrand F, et al. Beneficial effects of humidified high flow nasal oxygen in critical care patients: a prospective pilot study. Intensive Care Med 2011; 37: 1780-6.

19. Frat JP, Thille AW, Mercat A, et al. High-flow oxygen through nasal cannula in acute hypoxemic respiratory failure. $\mathrm{N}$ Engl $\mathrm{J}$ Med 2015; 372: 2185-96.

20. Patel A, Nouraei SA. Transnasal humidified rapid-insufflation ventilatory exchange (THRIVE): a physiological method of increasing apnoea time in patients with difficult airways. Anaesthesia 2015; 70: 323-9.

21. Gustafsson IM, Lodenius A, Tunelli J, Ullman J, Jonsson Fagerlund $M$. Apnoeic oxygenation in adults under general anaesthesia using transnasal humidified rapid-insufflation ventilatory exchange (THRIVE) - a physiological study. Br J Anaesth 2017; 118: 610-7.

22. Kim HJ, Asai T. High-flow nasal oxygenation for anesthetic management. Korean J Anesthesiol 2019. DOI:https://doi.org/10. 4097/kja.19174.

Publisher's Note Springer Nature remains neutral with regard to jurisdictional claims in published maps and institutional affiliations. 